\title{
(2) OPEN ACCESS \\ Prevalence of blindness and distance vision impairment in the Gambia across three decades of eye health programming
}

\author{
Abba Hydara, Islay Mactaggart 지, ${ }^{2}$ Suzannah J Bell 다, ${ }^{3}$ John A Okoh, \\ Segun I Olaniyan, ${ }^{4}$ Mildred Aleser, ${ }^{2}$ Hannaa Bobat, ${ }^{5}$ Andy Cassels-Brown, ${ }^{6,7}$ \\ Ben Kirkpatrick, ${ }^{3}$ Min J Kim, ${ }^{2}$ lan McCormick $\left({ }^{\circ},{ }^{2}\right.$ Hannah Faal, ${ }^{8}$ \\ Matthew J Burton (1) 2,9
}

\begin{abstract}
- Additional supplemental material is published online only. To view, please visit the journal online (http://dx.doi. org/10.1136/bjophthalmol2021-320008).
\end{abstract}

For numbered affiliations see end of article.

\section{Correspondence to}

Professor Matthew J Burton International Centre for Eye Health, London School of Hygiene \& Tropical Medicine, London, UK;

matthew.burton@Ishtm.ac.uk

Received 13 July 2021

Accepted 10 December 2021
Check for updates

(C) Author(s) (or their employer(s)) 2021. Re-use permitted under CC BY. Published by BMJ.

To cite: Hydara A, Mactaggart I, Bell SJ, et al. Br J Ophthalmol Epub ahead of print: [please include Day Month Year]. doi:10.1136/ bjophthalmol-2021-320008

\section{ABSTRACT \\ Background/aims The 1986 Gambia National Eye Health Survey provided baseline data for a National Eye Health Programme. A second survey in 1996 evaluated changes in population eye health a decade later. We completed a third survey in 2019, to determine the current state of population eye health, considering service developments and demographic change.}

Methods We estimated prevalence and causes of vision impairment (VI) in a nationally representative populationbased sample of adults 35 years and older. We used multistage cluster random sampling to sample 10800 adults 35 and above in 360 clusters of 30 . We measured monocular distance visual acuity (uncorrected and with available correction) using Peek Acuity. Participants with either eye uncorrected or presenting (with available correction) acuity $<6 / 12$ were retested with pinhole and refraction, and dilated exams were completed on all eyes by ophthalmologists using a direct ophthalmoscope, slit lamp and $90 \mathrm{D}$ lens.

Results We examined 9188 participants (response rate 83\%). The 2013 census age-sex adjusted prevalence of blindness (presenting acuity $<3 / 60$ in better seeing eye) was $1.2 \%(95 \% \mathrm{Cl} 0.9$ to 1.4$)$ and of moderate or severe $\mathrm{VI}(\mathrm{MSVI},<6 / 18$ to $\geq 3 / 60$ ) was $8.9 \%$ (95\% CI 9.1 to 9.7$)$. Prevalence of all distance $\mathrm{VI}(<6 / 12)$ was $13.4 \%$ (12.4-14.4). Compared with 1996, the relative risk of blindness decreased (risk ratio $0.7,95 \% \mathrm{Cl} 0.5$ to 1.0 ) and MSVI increased (risk ratio $1.5,95 \% \mathrm{Cl} 1.2$ to 0.17 ).

Conclusion Significant progress has been made to reduce blindness and increase access to eye health across the Gambia, with further work is needed to decrease the risk of MSVI.

\section{INTRODUCTION}

The Gambia is the smallest country on mainland Africa, with an estimated population of 2.3 million (2019). ${ }^{1}$ In 1986, a national survey of vision impairment (VI) provided baseline data for the inception of the National Eye Care Programme, now the National Eye Health Programme (NEHP). ${ }^{2}$ The allage national prevalence of blindness (visual acuity (VA) $<3 / 60$ in the better-seeing eye) was $0.7 \%$; the prevalence of moderate or severe vision impairment (MSVI, VA<6/18 to $\geq 3 / 60$ ) was $1.4 \%$. $^{2}$ In 1996 , a second national survey evaluated changes in population eye health following 10 years of programme implementation. $^{3}$ Compared with 1986, the national blindness prevalence had fallen to $0.4 \%$, while MSVI prevalence had increased to $1.6 \%{ }^{3}$ The main causes of blindness and MSVI in both surveys were cataract, aphakia, uncorrected refractive error and corneal scarring. ${ }^{23}$ However, between the two surveys, the proportion of blindness caused by cataract or trachoma decreased substantially in line with NEHP activities. ${ }^{23}$

The NEHP was launched as a three-tier system of primary, secondary and tertiary services. ${ }^{45}$ In 1993 , a capacity-building programme began training low and mid-grade ophthalmic personnel, with phased implementation from west to east. A comprehensive national Trachoma Control Programme was initiated in 1997 , leading to the elimination of trachoma as a public health problem in $2021 .^{6}$

At the community level, primary eye care training is offered to healthcare workers, including community health nurses, village health workers, traditional birth attendants and primary school teachers. ${ }^{3} 7$ Secondary care is delivered through minor and major health facilities, linked by mobile community health nurses. Eight secondary eye units (across all seven health regions) are each led by a senior ophthalmic medical assistant (SOMA), trained in cataract surgery. An optometrist or optometry technician-led vision centre was established in each health region between 2013 and $2019 .^{89}$

In 2007, the Sheikh Zayed Regional Eye Care Centre (SZRECC) opened near the capital, expanding ophthalmic training and delivery of ophthalmic services. Subspecialty ophthalmic services comprising paediatrics, glaucoma, medical retina, optometry and orthoptics were introduced through the Gambia-Swansea VISION 2020 Link programme in 2008. ${ }^{10}$ Glaucoma and medical retinal services were further developed in 2017 and are led by a glaucoma specialist. There are presently five full-time ophthalmologists in the Gambia, all stationed at SZRECC.

Changes in population demographics since the last survey include increasing population size, life expectancy and substantial urbanisation. ${ }^{1} 1112$ Considering these and NEHP service developments, we conducted the third National Eye Health Survey in 2019 , to determine the current state of eye health in the Gambia. 


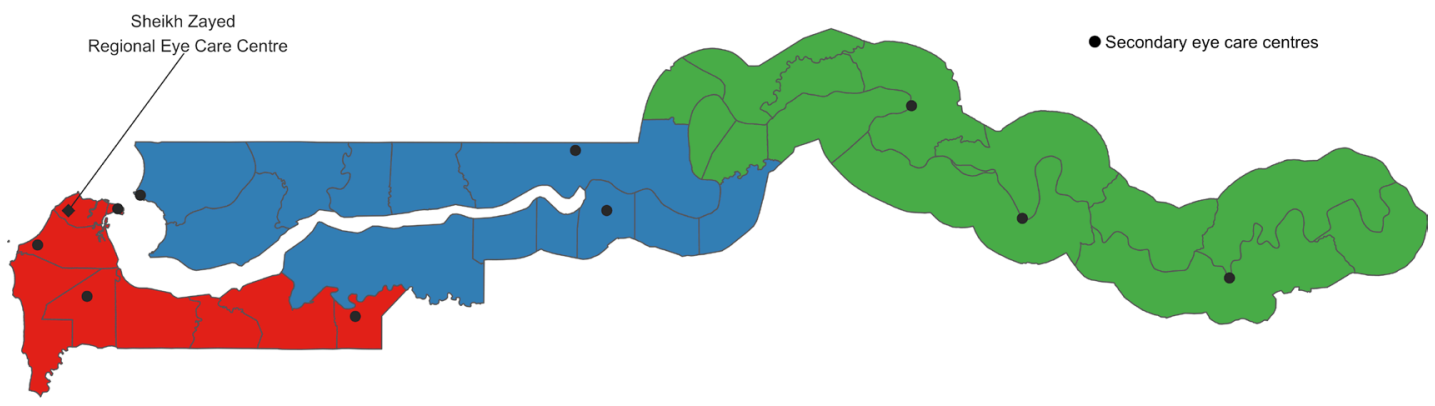

Historic regions $\square$ Western $\square$ Central $\square$ Eastern

Figure 1 Historic Regions of the Gambia (map generated in the statistical programme R using map data from GADM.org by lan McCormick)

\section{MATERIALS AND METHODS}

The purpose of this survey was to determine the prevalence and causes of VI in a nationally representative populationbased sample of adults 35 years and older in the Gambia, and to compare this with the situation in 1996.

\section{Study setting}

The Gambia is divided into eight local government areas (LGAs), with 1923 settlements. Since 1996, the administrative boundaries have changed, so to compare findings with previous surveys, we stratified the country into three historic regions: western, central and eastern (figure 1). Western included Brikama, Kanifing and Banjul LGAs. Central included Mansakonko and Kerewan, and eastern included Janjanbureh, Kuntaur and Basse.

\section{Sampling strategy and sample size}

The detailed survey protocol is reported elsewhere. ${ }^{13}$ In brief, we used the most recent available (2013) census data as the sampling frame, and conducted multistage stratified cluster random sampling, to select a nationally representative sample of adults 35 years and older (for comparability with previous surveys). We reviewed eye disease prevalence data from the region and powered the sample size to detect disease prevalence as low as $0.5 \% .^{31415}$ We estimated an intraclass correlation coefficient of 0.038 , design effect of 2.5, 20\% non-response and binomial exact distribution with an estimated margin of error of $0.25 \%$ to account for rare conditions $(\mathrm{p}<0.1)$ to arrive at an overall sample of 10800 adults age 35 and older in 360 clusters of 30 . We stratified the national sampling frame by urban/rural locality and broad region, selecting 360 clusters without replacement and with probability proportionate to size. Finally, we selected 30 participants per cluster via segmentation (see below).

\section{Team composition and training}

Four teams completed the data collection between February and July 2019. Each included an ophthalmologist, optometrist or optometry technician, SOMA, general nurse, mental health nurse and two enumerators. An audiology nurse joined one of the teams. Teams completed 10 days of training, including an interobserver variability test of VA measurement and pilot testing (detailed elsewhere), before the survey began. ${ }^{13}$

\section{Data collection procedures}

Enumeration Area (EA) maps were used by the enumerators to visit each cluster a day in advance of data collection, to complete a household listing of all eligible residents and identify a central location for the examination. Community members were eligible if they were 35 years or older, had resided in an EA household for at least 6 months of the preceding year, ate shared meals with other household members and did not pay or were not paid by other household members. Following listing, enumerators systematically segmented the list into groups of 30 participants and selected one group at random. Selected participants were given further information about the study and invited to attend the central location the following day.

Data collection procedures not related to this paper are described elsewhere. ${ }^{13}$ The team optometrist or optometry technician measured participants' VA indoors, without glare affecting either the participant or test chart. Monocular distance VA (uncorrected and wearing available correction) was measured using Peek Acuity. ${ }^{16}$ People with uncorrected (or corrected, if wearing spectacles) $\mathrm{VA}<6 / 12$ in either eye were retested with pinhole (lorgnette multi 17 occluder) and objective and subjective refraction using a streak retinoscope, trial lens set and wall chart (3 metre Snellen chart, Sussex Vision). We tested monocular best corrected VA with Peek Acuity following refraction. Near vision assessment will be reported separately.

Participants then underwent detailed ocular examination by an ophthalmologist. A desktop-mounted slit-lamp was used to document anterior segment eye disease or trachomatous trichiasis using a standardised eye health survey examination form, comparable with the 1996 data collection. ${ }^{13}$ Unless contraindicated by IOP $\geq 35 \mathrm{~mm} \mathrm{Hg}$ (measured via iCare ic100 Tonometer) or van Herrick's grade 2 or 1 , both pupils were then dilated using tropicamide 1\%, and a slit lamp and a 90 D lens were used to examine the lens and posterior segment.

Images were taken of the anterior (Nikon D5600 Digital camera with macro lens), and posterior segment (disc-centred and macula-centred, using the Remidio Retinal Camera). ${ }^{17}$

\section{Outcome measures and data analysis}

The main outcome measures and definitions are outlined in online supplemental appendix 1 and described in the relevant tables. Details on other study outcome measures, diagnoses and data management, preparation and dissemination are presented in full elsewhere. ${ }^{13}$

Data were analysed using STATA V.16.0. Prevalence estimates with $95 \%$ CIs were generated using the 'svyset' command to account for clustering. The survey oversampled women and older age groups, relative to their proportions in the population in general. Poststratification sample weights were calculated for 5 -year age-sex bands, multiplied by cluster selection probabilities to standardise the findings to the 2013 Gambia census. We also generated sampling weights to standardise the findings to the WHO standard population. ${ }^{13} 1819$ 
Age-disaggregated estimates are presented above and below 50 years of age, to align with recent global estimates and outputs from the Rapid Assessment of Avoidable Blindness. ${ }^{20} 21$ To estimate the magnitude of VI and blindness, adjusted prevalence estimates were extrapolated from intercensal population projections provided by the Gambia Bureau of Statistics. ${ }^{22}$ To compare outputs from the current survey to previous surveys, crude prevalence estimates for each were first age standardised to the 1986 sample. We then calculated adjusted risk differences and ratios for 1996 and 2019, using the 1986 estimates as denominators. P values for risk ratios (RRs) were generated via $\chi^{2}$ tests.

\section{RESULTS}

We examined 9188 participants out of 11027 eligible, enumerated participants (response rate 83\%). Sample characteristics are reported in detail elsewhere. ${ }^{13}$ In brief, the mean age of the examined sample was 49.6 years (SD) 13.4) and 6478 $(70.5 \%)$ were female. Response rates were lower than expected in several age groups and clusters. However, the sample from the three regions and the representation of the main ethnic groups reflected the 2013 census distributions, and 5039 (54.8\%) lived in urban locations.

Table 1 shows crude and census age-sex weighted prevalence estimates for distance VI and blindness in the population 35 years and older across the Gambia. Estimates weighted using the WHO standard population were similar to the censusweighted estimates, and therefore, we only present crude and census-weighted estimates throughout (see online supplemental appendix 2 for WHO weighted estimates by region). The weighted prevalence of blindness was $1.2 \%$ (95\% CI) $0.9 \%$ to $1.4 \%)$; moderate or severe vision impairment (MSVI) was $8.9 \%$ (95\% CI 8.1\% to 9.7\%); and mild VI was 3.3\% (95\% CI 3.0\% to $3.8 \%)$. The total weighted prevalence of any distance VI was $13.4 \%$ (95\% CI $12.4 \%$ to $14.4 \%$ ). Extrapolating to the 2019 Gambian population, this gives an estimated 5405 people $35+$ who are blind and 60360 with any distance VI.

The weighted prevalence of any VI was lower in eastern region $(10.3 \%, 95 \%$ CI $8.8 \%$ to $12.0 \%)$ than central $(16.2 \%, 95 \% \mathrm{CI}$ $13.1 \%$ to $19.8 \%)$ or western $(13.9 \%, 95 \%$ CI $12.8 \%$ to $15.2 \%)$ regions. There were no differences in the weighted prevalence of MSVI or blindness between the three major regions but mild VI prevalence was lower in eastern region $(2.0 \%$, 95\% CI 1.5\% to $2.8 \%$ ) than western region $(3.7 \%, 95 \% \mathrm{CI} 3.2 \%$ to $4.3 \%)$ or central region $(4.1 \%, 95 \%$ CI $3.0 \%$ to $5.6 \%)$.

The weighted prevalence of any VI and MSVI was higher in women than men (women: any VI $14.0 \%$ (95\% CI $13.2 \%$ to $14.9 \%$ ), MSVI $11.2 \%$ (95\% CI $10.2 \%$ to $12.4 \%$ ); men: any VI $10.8 \%$ (95\% CI $9.7 \%$ to $12.0 \%$ ), MSVI $6.5 \%$ (95\% CI $5.7 \%$ to $7.5 \%)$. The prevalence of mild VI and blindness were similar by sex. There were no prevalence differences between rural and urban settings for any VI category. The prevalence of all levels of VI was substantially higher in people aged 50 years and older compared with those 35-49 years (table 2).

To report temporal trends, table 3 presents the crude national prevalence of blindness and MSVI (termed 'low vision' in earlier surveys) by age group in 1986, 1996 and 2019. To enable comparisons between surveys, we also provide the prevalence estimates for the 1996 and 2019 surveys, standardised to the 1986 age structure. The relative risk of blindness calculated across the adjusted estimates was similar between 1986 and 1996 (risk ratio (RR) $0.8,95 \%$ CI 0.6 to 1.2 ) but decreased between 1996 and 2019 (RR 0.7, 95\% CI 0.5 to 1.0 ). The relative risk of MSVI increased between 1986 and 1996 (RR 1.3, 95\% CI 1.0 to

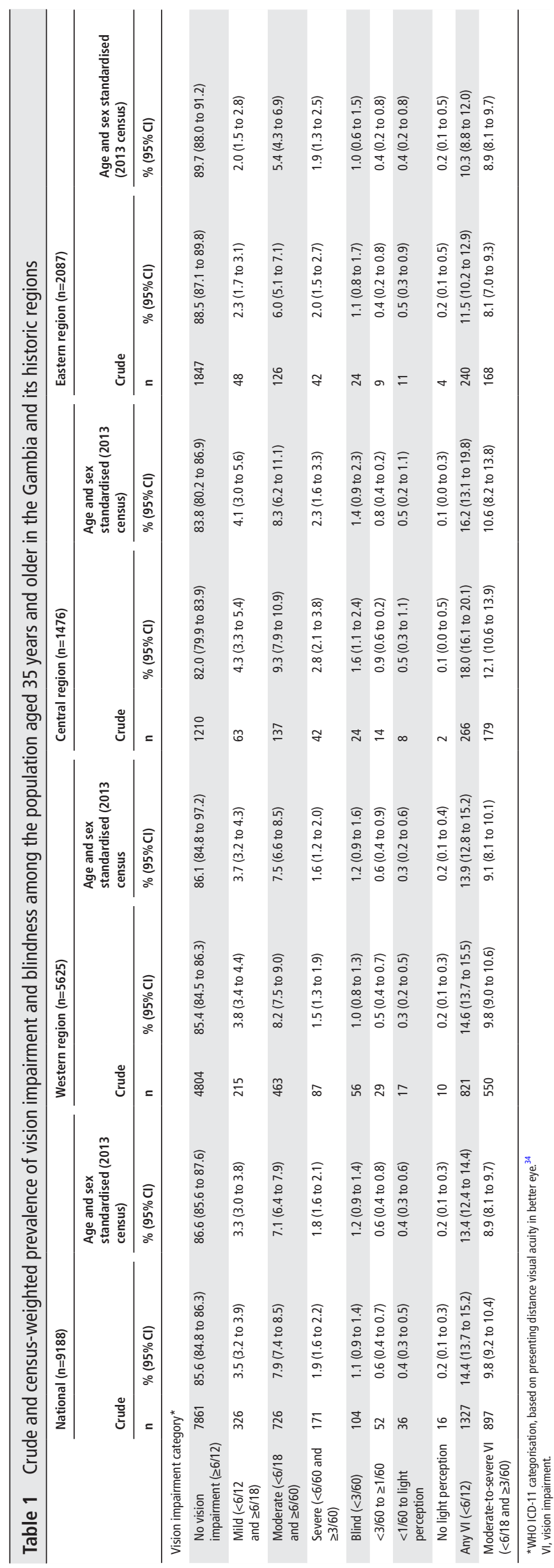




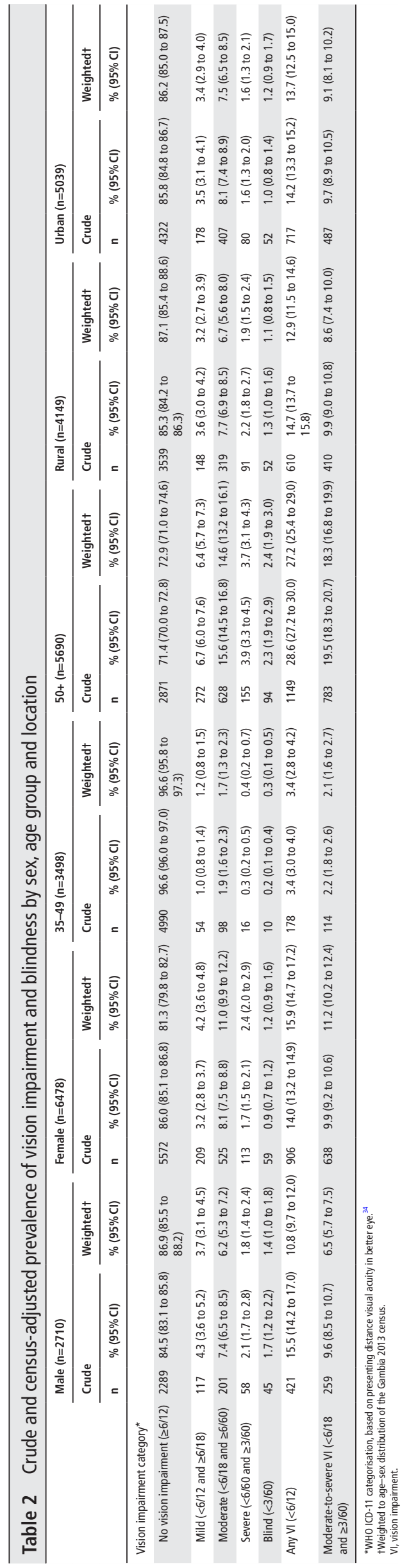

1.6), and between 1996 and 2019 (RR 1.5, 95\% CI 1.2 to 1.7). Compared with 1986, the 2019 relative risk of blindness was 0.5 (95\% CI 0.3 to 0.7 ), and of MSVI was 1.9 (95\% CI 1.6 to 2.3).

In 2019, cataract was the main cause of blindness $(71.0 \%)$, severe VI (67.2\%), moderate VI (49.9\%) and VI overall (44.6\%), while refractive error was the main cause of mild VI (83.3\%). More than two-thirds (68.8\%) of people with any VI had more than one cause contributing to their vision loss (table 4).

\section{DISCUSSION}

The census-weighted prevalence of blindness in adults aged 35 years and older in the Gambia in 2019 was 1.2\% (0.9-1.4), while the prevalence of MSVI was $8.9 \%$ (8.1-9.7). There have been no comprehensive eye health surveys in sub-Saharan Africa in the last decade with which to compare this estimate. ${ }^{23}$ Metaanalyses by the Vision Loss Expert Group (VLEG) in 2020 estimated the all-age prevalence of blindness in western sub-Saharan Africa at $1.1 \%(1.0-1.3)$, and the all-age prevalence of MSVI in the region at $4.1 \%(3.6-4.5){ }^{24}$ These estimates are not directly comparable, due to low prevalence in children and younger adults reducing all-age estimates, compared with those in adult subgroups only. VLEG also estimates that the prevalence of blindness in the population 50 years and older in the region is $4.2 \%(3.5-4.9)$ and MSVI is $14.4 \%(12.7-16.3){ }^{20}$ In comparison, our study estimated the weighted prevalence of blindness in this age group as 2.4\% (1.9-3.0), and MSVI 18.3\% (16.8-19.9).

While prevalence of mild VI was higher in eastern region than other regions, we otherwise detected few differences in the prevalence of each level of VI by broad geographic region or rural vs urban location. The absence of subnational discrepancies in prevalence validates the NEHP's approach to tiered, regional eye health service provision, including stationing midlevel ophthalmic personnel to perform surgeries throughout the country, and ensuring effective referral between levels.

The prevalence of moderate VI in our survey was higher in women than men $(11.0 \%(9.9-12.2)$ vs $6.2 \%(5.3-7.2))$ but $\mathrm{VI}$ prevalence was otherwise similar by sex. This latter finding is encouraging, given commonly documented gender inequity in accessing eye health services globally. ${ }^{25}$ The 1986 Gambian survey reported an all-age, age-standardised 1.6:1 ratio of $\mathrm{VI}$ $(<6 / 18)$ in women versus men $(2.5 \%$ vs $1.6 \%)$, attributed by the authors predominantly to differences in health-seeking behaviour for cataract and trachoma treatment. ${ }^{2}$ Changing patterns of disease (for example declining contribution of trachoma to VI) and increasing service provision may be responsible for reducing some gender inequality, although the higher estimate for moderate VI in women requires further investigation.

The Gambian population has almost tripled between 1986 and $2019^{218}$ and a parallel rise in life expectancy has increased both the absolute number of older people and the older population as a proportion of the all-age population. ${ }^{26}$ Despite this increase in the population with expected eye health service needs, the relative risk of blindness in 2019 is 30\% lower than 1996 (RR 0.7, 0.5-1.0) and has halved compared with 1986 (RR 0.5, 0.3-0.7). In 2020 VLEG estimated a $27.3 \%$ (26.428.0) reduction in blindness in the region between 1990 and $2019 .{ }^{24}$ The prevalence of MSVI in the Gambia (standardised to the 1986 Census population) increased slightly between 1986 and 1996 (4.5\%-6.0\%, RR 1.3, 1.0-1.7) but remained similar between 1996 and 2019 (RR 1.3, 1.0-1.6). By comparison, VLEG estimated a $3.4 \%(2.8-4.0)$ reduction in age-standardised MSVI in the region over this period. ${ }^{24}$ The NEHP has had a positive impact on population eye health in terms of blindness 
Table 3 Relative risk of blindness and MSVI nationally by age 1986, 1996 and 2019

\begin{tabular}{|c|c|c|c|c|c|c|c|c|c|}
\hline & \multicolumn{3}{|c|}{ Sample examined } & \multicolumn{3}{|c|}{ Blindness (crude) } & \multicolumn{3}{|c|}{ MSVI (crude) } \\
\hline & 1986 & 1996 & 2019 & 1986 & 1996 & 2019 & 1986 & 1996 & 2019 \\
\hline Age & $\mathbf{n}$ & $\mathbf{n}$ & $\mathbf{n}$ & $\%$ & $\%$ & $\%$ & $\%$ & $\%$ & $\%$ \\
\hline $30-39+$ & 807 & 1303 & 2249 & 0.4 & 0.4 & 0.1 & 0.9 & 0.4 & 1.2 \\
\hline $40-49$ & 590 & 842 & 3096 & 1.0 & 0.2 & 0.3 & 1.9 & 2.1 & 2.7 \\
\hline $50-59$ & 407 & 496 & 1741 & 1.5 & 1.9 & 0.6 & 4.2 & 6.5 & 8.0 \\
\hline $60-69$ & 255 & 369 & 1154 & 3.9 & 3.5 & 1.2 & 8.6 & 12.1 & 18.0 \\
\hline $70+$ & 226 & 278 & 948 & 9.7 & 7.5 & 7.1 & 19.9 & 28.1 & 37.6 \\
\hline Crude prevalence & & & & $\begin{array}{l}2.1 \\
\text { (1.5 to } 2.6)\end{array}$ & $\begin{array}{l}1.5 \\
\text { (1.1 to } 2.0)\end{array}$ & $\begin{array}{l}1.2 \\
(0.9 \text { to } 1.4)\end{array}$ & $\begin{array}{l}4.5 \\
\text { (3.6 to } 5.3 \text { ) }\end{array}$ & $\begin{array}{l}5.4 \\
(4.7 \text { to } 6.2)\end{array}$ & $\begin{array}{l}8.9 \\
(8.3 \text { to } 9.5)\end{array}$ \\
\hline Age-standardised prevalence $\ddagger$ & & & & - & $\begin{array}{l}1.7 \\
\text { (1.2 to } 2.1)\end{array}$ & $\begin{array}{l}1.1 \\
\text { (0.9 to } 1.3)\end{array}$ & - & $\begin{array}{l}6.0 \\
(5.2 \text { to } 6.8)\end{array}$ & $\begin{array}{l}8.3 \\
\text { (7.9 to } 8.8)\end{array}$ \\
\hline Risk ratio (compared with 1986)§ & & & & - & $\begin{array}{l}0.8 \\
(0.6 \text { to } 1.2)\end{array}$ & $\begin{array}{l}0.5^{* *} \\
(0.3 \text { to } 0.7)\end{array}$ & - & $\begin{array}{l}1.3^{*} \\
(1.0 \text { to } 1.6)\end{array}$ & $\begin{array}{l}1.9^{* *} \\
(1.6 \text { to } 2.3)\end{array}$ \\
\hline Risk difference (compared with 1986)ף & & & & - & $\begin{array}{l}-0.004 \\
(-0.011 \text { to } 0.003)\end{array}$ & $\begin{array}{l}-0.009 \\
(-0.015 \text { to }-0.003)\end{array}$ & - & $\begin{array}{l}0.135 \\
(0.002 \text { to } 0.025)\end{array}$ & $\begin{array}{l}0.387 \\
(0.029 \text { to } 0.048)\end{array}$ \\
\hline Risk ratio (compared with 1996)§ & & & & & - & $0.7^{*}(0.5$ to 1.0$)$ & & - & $1.5(1.2 \text { to } 1.7)^{* *}$ \\
\hline Risk difference (compared with 1996)ף & & & & & - & $\begin{array}{l}-0.005 \\
(-0.010 \text { to }-0.000)\end{array}$ & & - & $\begin{array}{l}0.252 \\
(0.016 \text { to } 0.346)\end{array}$ \\
\hline
\end{tabular}

NB 1996 and 1986 comparison data generated from unpublished survey data provided by H Faal.

${ }^{*} \mathrm{p}<0.05$ from $\chi^{2}$ test.

+35-39 in 2019.

¥Age standardised to 1986 sample.

$\S$ Age-standardised prevalence risk ratio.

१Age-standardised prevalence risk difference.

${ }^{* *} \mathrm{p}<0.001$ from $\chi^{2}$ test.

MSVI, moderate or severe vision impairment.

reduction, but in contrast to regional estimates, has not seen a similar decline in MSVI. Maintaining the impressive progress in treating those most severely impaired while managing the effects of population growth and ageing on an increasing magnitude of moderate and severe impairment will be a planning priority over the coming decades.
Comparisons with the 1986 and 1996 surveys also highlight changes in the proportion of blindness by cause over time. In $2019,71 \%$ of blindness was due to cataract, a reversal of the modest decline in the proportion from 55\% to $45 \%$ between 1986 and 1996 but in line with recent Global Burden of Disease (GBD) estimates that cataract continues to be the leading cause

Table 4 Main causes of blindness and vision impairment (adjusted number of cases* and proportions by level of vision impairment) in the Gambia in 2019

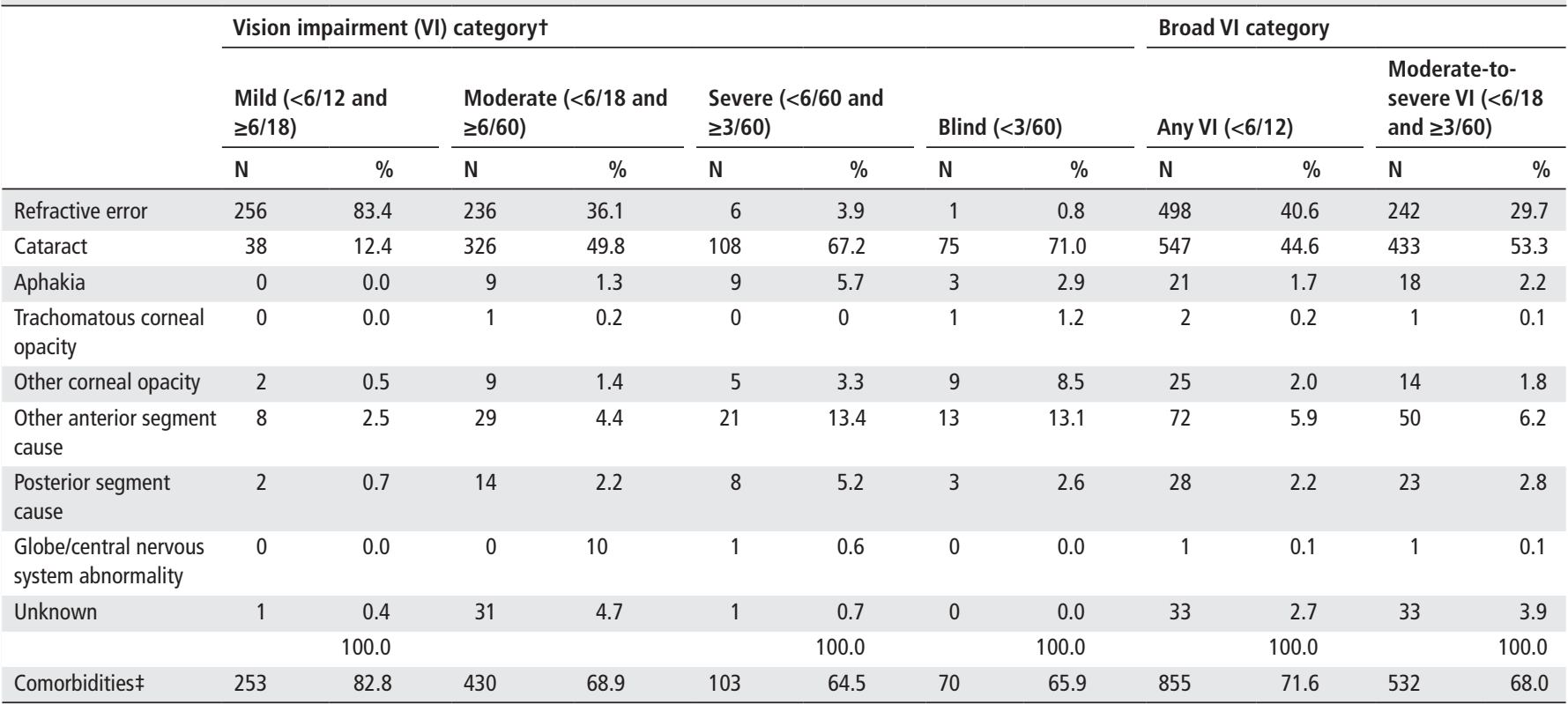

${ }^{*} \mathrm{~N}$ and \% are based on the weighted sample, after correcting the age/sex imbalance in 2019 using the Gambia 2013 census. tWHO ICD-11 categorisation, based on presenting distance visual acuity in better eye. ${ }^{34}$

‡The presence of at least 1 of 12 main causes in same person. 
of blindness in the region. ${ }^{23}$ High-volume manual small incision cataract surgery has been performed in the Gambia since 2015, but the current surgical threshold is $6 / 60$ in most facilities $(6 / 18$ in SZRECC). ${ }^{27}$ The enduring high proportion of VI attributed to cataract warrants revision of these guidelines, and a focus on further expansion of cataract surgical services. ${ }^{28}$

In contrast, and contributing to the increased proportion of blindness caused by cataract, declining proportions of other avoidable causes of blindness highlights strengths of the NEHP. Trachoma was responsible for $17 \%$ of blindness in $1986,5 \%$ in 1996 and 1\% (1 case) in 2019. ${ }^{23}$ NEHP's commitment to the SAFE strategy ${ }^{2930}$ has recently seen the Gambia become only the second sub-Saharan African country to eliminate trachoma as a public health problem. Similarly, uncorrected aphakia was the cause of $8 \%$ of blindness in 1986 and $13 \%$ in $1996 .^{23}$ By 2019, only 2 cases were identified as causes of VI, suggesting improved surgical outcomes with increased use of intraocular lenses. ${ }^{31}$

Despite the achievements of the Regional Ophthalmic Training Programme, there is anecdotal evidence of depleted eye health personnel in community and secondary facilities nationally, which undoubtably affects service coverage overall. Motivation and retention of competent and committed personnel is essential to integrate eye care into universal health coverage, support effective eye care delivery, and achieve universal eye health. ${ }^{32} 33$ Ensuring adequate career progression, availability of programme resources and full integration of services into primary and secondary health facilities are all strategies that can support the NEHP to continue tackling avoidable VI. ${ }^{32}$

This large, comprehensive survey provides rich data on population eye health in the Gambia in 2019, and allows comparison of changes in VI and blindness over time. However, under sampling in certain age groups and clusters necessitated the use of sampling weights in reporting estimates.

In conclusion, the 2019 Gambia National Eye Health Survey demonstrated a reduction in the prevalence of blindness compared with 1986 and 1996. There was no significant difference in the prevalence of VI or blindness across the regions or by urban/rural locations, indicating strong national coverage by the NEHP. Huge progress has been made to achieve the elimination of trachoma as a public health problem in 2021. Now, the volume of quality cataract surgery needs to increase to address the leading cause of blindness and MSVI. The infrastructure required to avoid subnational eye health inequality appears to be in place, but a national strategy for early intervention via modern cataract surgical services is necessary and targeted interventions to reduce gender inequality in moderate impairment may be needed.

\author{
Author affiliations \\ ${ }^{1}$ Sheikh Zayed Regional Eye Care Centre, Banjul, Gambia \\ ${ }^{2}$ International Centre for Eye Health, London School of Hygiene \& Tropical Medicine, \\ London, UK \\ ${ }^{3}$ Moorfields Eye Hospital NHS Foundation Trust, London, UK \\ ${ }^{4}$ Department of Ophthalmology, University College Hospital Ibadan, Ibadan, Oyo, \\ Nigeria \\ ${ }^{5}$ St Mary's Hospital, Isle of Wight NHS Trust, Newport, UK \\ ${ }^{6}$ The Fred Hollows Foundation, Sydney, New South Wales, Australia \\ ${ }^{7}$ Department of Ophthalmology, NHS Highland, Inverness, UK \\ ${ }^{8}$ Department of Ophthalmology, University of Calabar, Calabar, Cross River, Nigeria \\ ${ }^{9}$ National Institute for Health Research Biomedical Research Centre for \\ Ophthalmology, Moorfields Eye Hospital NHS Foundation Trust, London, UK
}

\section{Twitter Abba Hydara @HydaraAbba}

Contributors MJB, IM and AH conceptualised the study. MJB acquired the funding. $A H, I M, I M C C$ and $M J B$ drafted and edited the manuscript. IM and MJK analysed the data. SJB, JAO, SIO, MA, HB, AC-B, BK and HF contributed to the data collection and reviewed and commented on the manuscript. MJB is the guarantor for this study.

Funding This research was funded by The Queen Elizabeth Diamond Jubilee Trust (TG002). MJB is supported by the Wellcome Trust [207472/Z/17/Z].

Map disclaimer The inclusion of any map (including the depiction of any boundaries therein), or of any geographic or locational reference, does not imply the expression of any opinion whatsoever on the part of BMJ concerning the legal status of any country, territory, jurisdiction or area or of its authorities. Any such expression remains solely that of the relevant source and is not endorsed by BMJ. Maps are provided without any warranty of any kind, either express or implied.

Competing interests None declared.

Patient consent for publication Not applicable.

Ethics approval This study involves human participants and was approved by The survey was approved by the Gambia Government/Medical Research Council Joint Ethics and Scientific Coordinating Committee (reference: SCC 1635) and the Observational/Interventions Research Ethics Committee of the London School of Hygiene \& Tropical Medicine (reference: 16172). The exercise was fully compliant with the Declaration of Helsinki on ethical principles for medical research involving human subjects, including research on identifiable human material and data. Participants gave informed consent to participate in the study before taking part. Written informed consent was collected by fingerprint or signature for each available participant.

Provenance and peer review Not commissioned; externally peer reviewed.

Data availability statement Data are available upon reasonable request. Data analyses are ongoing. The anonymised dataset can be made available on reasonable request from the study team.

Supplemental material This content has been supplied by the author(s). It has not been vetted by BMJ Publishing Group Limited (BMJ) and may not have been peer-reviewed. Any opinions or recommendations discussed are solely those of the author(s) and are not endorsed by BMJ. BMJ disclaims all liability and responsibility arising from any reliance placed on the content. Where the content includes any translated material, BMJ does not warrant the accuracy and reliability of the translations (including but not limited to local regulations, clinical guidelines, terminology, drug names and drug dosages), and is not responsible for any error and/or omissions arising from translation and adaptation or otherwise.

Open access This is an open access article distributed in accordance with the Creative Commons Attribution 4.0 Unported (CC BY 4.0) license, which permits others to copy, redistribute, remix, transform and build upon this work for any purpose, provided the original work is properly cited, a link to the licence is given, and indication of whether changes were made. See: https://creativecommons.org/ licenses/by/4.0/.

\section{ORCID iDs}

Islay Mactaggart http://orcid.org/0000-0001-6287-0384

Suzannah J Bell http://orcid.org/0000-0002-3328-3698

lan McCormick http://orcid.org/0000-0002-7360-3844

Matthew J Burton http://orcid.org/0000-0003-1872-9169

\section{REFERENCES}

1 The World Bank Group.. The world bank data bank, 2021. Available: https://data. worldbank.org/indicator/SP.POP.TOTL?locations=GM

2 Faal H, Minassian D, Sowa S, et al. National survey of blindness and low vision in the Gambia: results. Br J Ophthalmol 1989;73:82-7.

3 Faal H, Minassian DC, Dolin PJ, et al. Evaluation of a national eye care programme: re-survey after 10 years. Br J Ophthalmol 2000;84:948-51.

4 Gambia Department of State for Health and Social Welfare. The Gambia social sector consultation background documents. vol. 2 - health. 1998-2003. Banjul, The Gambia: Gambia Ministry of Health, 1998

5 Gambia Department of State for Health and Social Welfare.. The Gambia health policy 2012 to 2020. Banjul, The Gambia: Gambia Ministry of Health;, 2012.

6 World Health Organisation. WHO validates Gambia for having eliminated trachoma as a public health problem, 2021.

7 Hannah Faal Gambia Department of State for Health and Social Welfare. NECP Coordinator's Annual Report 1994. Banjul, The Gambia: Gambia Ministry of Health, 1994.

8 Sustainable Goals. Vision for the Gambia: OneSight brings vision care to an entire country, 2017. https://www.sustainablegoals.org.uk/

9 Bowser D, Landey N, Njie MA, et al. Health system strengthening for vision care in the Gambia. Rural Remote Health 2021;21:6245.

10 Swansea-Gambia Link. Swansea-Gambia link: a partnership between medical schools, 2021.

11 World Health Organisation. Global health Observatory data Repository: the Gambia, 2018. 
12 The Gambia Bureau of Statistics (GBOS) and ICF International. The Gambia demographic and health survey 2013. Banjul, The Gambia, and Rockville, Maryland, USA: GBOS and ICF International, 2014.

13 Hydara A, Bastawrous A, Bell S. The Gambia National Eye Health Survey 2019: survey protocol [version 1; peer review: 2 approved with reservations]. Wellcome Open Research 2021;6:10.

14 Tham Y-C, Li X, Wong TY, et al. Global prevalence of glaucoma and projections of glaucoma burden through 2040: a systematic review and meta-analysis. Ophthalmology 2014;121:2081-90.

15 Mathenge W, Bastawrous A, Peto T, et al. Prevalence and correlates of diabetic retinopathy in a population-based survey of older people in Nakuru, Kenya. Ophthalmic Epidemiol 2014;21:169-77.

16 Bastawrous A, Rono HK, Livingstone IAT, et al. Development and validation of a smartphone-based visual acuity test (peek acuity) for clinical practice and communitybased fieldwork. JAMA Ophthalmol 2015;133:930-7.

17 Prathiba V, Rajalakshmi R, Arulmalar S, et al. Accuracy of the smartphone-based nonmydriatic retinal camera in the detection of sight-threatening diabetic retinopathy. Indian J Ophthalmol 2020;68:42.

18 Gambia Bureau of Statistics. The Gambia 2013 population and housing census preliminary results. In: Gambia Bureau of statistics Serre Kunda. The Gambia, 2013.

19 Ahmad OB, Boschi-Pinto C, Lopez AD. Age standardization of rates: a new WHO standard. Geneva: World Health Organization, . 2001.

20 GBD 2019. Blindness and vision impairment collaborators on behalf of the vision loss expert group of the global burden of disease study (VLEG-GBD). trends in prevalence of blindness and distance and near vision impairment over 30 years: an analysis for the global burden of disease study. The Lancet Global Health 2021;9.

21 Mactaggart I, Limburg H, Bastawrous A, et al. Rapid assessment of avoidable blindness: looking back, looking forward. Br J Ophthalmol 2019;103:1549-52.

22 Gambia Bureau of Statistics. Projected Population 2014- 2025_01 November 2019. In: Gambia Ministry of health TG, 2021

23 Burton M, Ramke J, Marques AP. Supplementary appendix 1. supplement to: Burton MJ, Ramke J, Marques AP, et al. The Lancet global health Commission on global eye health: vision beyond 2020. Lancet Glob Health 2021.
24 GBD 2019 Blindness and Vision Impairment Collaborators, Vision Loss Expert Group of the Global Burden of Disease Study. Causes of blindness and vision impairment in 2020 and trends over 30 years, and prevalence of avoidable blindness in relation to vision 2020: the right to sight: an analysis for the global burden of disease study. Lancet Glob Health 2021;9:e144-60.

25 Ramke J, Zwi AB, Palagyi A, et al. Equity and blindness: closing evidence gaps to support universal eye health. Ophthalmic Epidemiol 2015;22:297-307.

26 Bourne RRA, Flaxman SR, Braithwaite T, et al. Magnitude, temporal trends, and projections of the global prevalence of blindness and distance and near vision impairment: a systematic review and meta-analysis. Lancet Glob Health 2017:5:e888-97.

27 Gambia Department of State for Health and Social Welfare. National Eye Health Programme Manager's Annual Report - NEHP Key Performance Indicators (KPIS) 2018. Banjul, The Gambia: Gambia Ministry of Health, 2018.

28 Burton MJ, Ramke J, Marques AP, et al. The Lancet global health Commission on global eye health: vision beyond 2020. The Lancet Global Health 2021;9:e489-551.

29 Migchelsen SJ, Sepúlveda N, Martin DL, et al. Serology reflects a decline in the prevalence of trachoma in two regions of the Gambia. Sci Rep 2017;7:1-10.

30 mondiale de la Santé O, Organization WH. WHO Alliance for the Global Elimination of Trachoma by 2020: progress report, 2019360 COVID-19 update-Alliance de I'OMS pour l'élimination mondiale du trachome d'ici 2020: Rapport de situation, 2019 360 Le point sur la maladie coronavirus 2019 (COVID-19). . Weekly Epidemiological Record, 2020: 95. 349-60.

31 Faal HB. The Gambia: approaches to blindness. The Lancet 1997;349:S23.

32 Burton MJ, Ramke J, Marques AP, et al. The Lancet global health Commission on global eye health: vision beyond 2020. Lancet Glob Health 2021;9:e489-551.

33 Lancet T. A vision for universal eye health, 2019.

34 World Health Organisation. The International Classification of Diseases and Related Health Problems (ICD) for Mortality and Morbidity Statistics - Version 11 World Health Organisation, 2021. Available: https://icd. who.int/browse11/l-m/en 